\title{
Constitucionalismo, hiperpresidencialismo y desequilibrio de poderes en Brasil en tiempos de la pandemia de COVID-19
}

Constitutionalism, hyper-presidentialism and imbalance of powers in Brazil at the time of the COVID-19 pandemic

Autor: Graça Maria Borges de Freitas

DOl: https://doi.org/10.19053/16923936.v18.n36.2020.12160

Para citar este artículo:

Freitas, G. M. B. (2020). Constitucionalismo, hiperpresidencialismo y desequilibrio de poderes en Brasil en tiempos de la pandemia de COVID-19. Derecho y Realidad, 18, (36), 111- 137. 


\title{
Constitucionalismo, hiperpresidencialismo y desequilibrio de poderes en Brasil en tiempos de la pandemia de COVID-19*
}

\author{
Constitutionalism, hyper-presidentialism and imbalance of powers in Brazil at the time of \\ the COVID-19 pandemic
}

Constitucionalismo, hiper-presidencialismo e desequilibrio de poderes no Brasil em tempos de pandemia COVID-19

\author{
Graça Maria Borges de Freitas ${ }^{\mathbf{a}}$ \\ gmariabfreitas@gmail.com
}

Recepción: 05 de octubre 2020

Aceptación: 20 de octubre 2020

\section{RESUMEN}

La pandemia del coronavirus es fruto de un modelo político y económico que genera degradación ambiental, económica y social lo que, a su vez, agrava las crisis que él mismo genera, en un círculo vicioso. Su ocurrencia reveló problemas estructurales de la política y de la economía y sirve para explicitar los grandes desafíos que la humanidad, en general, y América Latina, en particular, necesitan enfrentar para la superación del modelo vigente. Brasil representa un caso paradigmático para discutir los efectos perversos del modelo político y económico para la democracia y la efectividad de los derechos económicos, sociales, culturales y ambientales (DESCA) en un país cuyo diseño institucional de los tres poderes y la cultura jurídica y política no favorecen la protección de los derechos fundamentales, lo que quedó evidenciado por la forma como se dio el enfrentamiento de la pandemia por un gobierno de perfil autocrático y por las dificultades de los demás poderes para contener los efectos perversos de las prácticas abusivas del dirigente de ocasión.

\section{PALABRAS CLAVES}

Constitucionalismo; neoliberalismo; capitalismo financiero; hiperpresidencialismo abusivo; desequilibrio de poderes; COVID-19.

\section{ABSTRACT}

The coronavirus pandemic is the result of a political and economic model that generates environmental, economic and social degradation, which at the same time,

* Artículo de reflexión.

a. Doctora en Derecho por la Universidad Externado de Colombia, en cotutela internacional y doble titulación con la Universidad Federal de Minas Gerais. Magistrada Laboral en Brasil, desde 1997. 
aggravates the crises it generates, producing a vicious circle. Its occurrence revealed structural, political and economic problems, which explained the great challenges that humanity, in general, and Latin America, in particular, need to face in order to overcome the current model. Brazil represents a paradigmatic case for discussing the perverse effects of the political and economic model on democracy and the effectiveness of economic, social, cultural, and environmental rights (ESCR). This is especially true in a country whose institutional design of the three powers and legal culture do not favour the protection of fundamental rights. This is evidenced by the way in which the pandemic was confronted by an autocratic government. In addition to the difficulties of the powers that be to contain the perverse effects of the abusive practices of the former leader.

\section{KEYWORDS}

Constitutionalism; neoliberalism; financial capitalism; abusive hyperpresidentialism; imbalance of powers; COVID-19.

\section{RESUMO}

A pandemia do coronavírus é resultado de um modelo político e econômico que gera degradação ambiental, econômica e social, que, por sua vez, agrava as crises que ele mesmo gera, em um círculo vicioso. Sua ocorrência revelou problemas estruturais da política e da economia e serve para explicitar os grandes desafios que a humanidade, em geral, e a América Latina, em particular, precisam enfrentar para superar o modelo atual. 0 Brasil representa um caso paradigmático para discutir os efeitos perversos do modelo político e econômico para a democracia e a efetividade dos direitos econômicos, sociais, culturais e ambientais (DESCA) em um país cujo desenho institucional dos três poderes e a cultura jurídica e política não favorecem a proteção dos direitos fundamentais, o que ficou evidenciado pela forma como a pandemia foi enfrentada por um governo autocrático e pelas dificuldades dos demais poderes em conter os efeitos perversos das práticas abusivas do atual dirigente.

\section{PALAVRAS-CHAVE:}

Constitucionalismo; neoliberalismo; capitalismo financeiro; hiper-presidencialismo abusivo; desequilíbrio de poderes; COVID-19.

\section{SUMARIO}

1. Brasil en números durante la pandemia.

2. Antecedentes de la crisis actual - El constitucionalismo neoliberal financiero se impone por medio de reformas constitucionales y legales y de gobiernos autocráticos.

3. Autoritarismo, exclusión de las minorías, subalternidad y desequilibrio de poderes - la herencia colonial, los escombros de la dictadura y la incompleta transición democrática de Brasil - desafíos urgentes a superar.

4. La resistencia democrática y las lecciones de la crisis - el papel del congreso $\mathrm{y}$ del tribunal constitucional ante un hiperpresidencialismo abusivo - elementos para entender los desafíos de la protección de los derechos fundamentales y de la democracia participativa y sustantiva en Brasil.

Consideraciones finales - a propósito de buscar salidas para las crisis.

Referencias bibliográficas.

\section{BRASIL EN NÚMEROS DURANTE LA PANDEMIA}

Brasil es el país más grande de América Latina, en extensión territorial y en población. Según los últimos datos compilados por el IBGE $^{1}$, la población estimada del país supera hoy la marca de 211 millones de habitantes, distribuidos, desigualmente, en un territorio

1. Instituto Brasileiro de Geografia e Estatística - Datos disponibles en < www.ibge.gov.br>. 
de más de ocho millones y medio de kilómetros cuadrados. Apenas el Estado de São Paulo posee una población de más de 46 millones de habitantes, superior a la de muchos países de la región, como es el caso de Argentina.

A pesar de las dimensiones del país, los números de la pandemia en Brasil no impresionan solamente por los datos absolutos. Al contrario, son objeto de críticas negativas por su desproporción con relación a los promedios mundial y regional, especialmente, en cuanto a las muertes por miles de habitantes y la afectación de algunos grupos específicos, como los indígenas, los profesionales de salud, mujeres embarazadas o puérperas víctimas fatales de la enfermedad.

En el momento en que este artículo es escrito $^{2}$, Brasil recién ultrapasó el número oficial de 100.000 (cien mil) muertes por COVID-19. Es probable que cuando salga a la luz, en dos o tres meses más, el número de muertes sea equivalente al doble del número actual, si nada cambia en la conducción de la política sanitaria ${ }^{3}$.

La COVID-19 es la principal causa de mortalidad en el país y superó, en seis meses, por ejemplo, el número de muertes por SIDA durante los últimos nueve años (Paraguassu y Fonseca, 2020). Las cifras oficiales indican que las muertes diarias por COVID-19 superan, inclusive, aquellas procedentes de cánceres y enfermedades cardiovasculares (Kruse, 2020), que eran las causas predominantes de decesos en el país antes del pico de la pandemia. Además, por la afectación sistémica que el virus SARS-CoV-2 causa en el cuerpo humano ${ }^{4}$, muertes no investigadas - inclusive por infarto -, pueden enmascarar los números de la pandemia.

2. Los datos contenidos en ese artículo fueron colectados entre 09 y 31.08.2020. Al final del mes de agosto el número de muertos era de 120.000 personas.

3. Alerta que hizo Jesem Orellana, epidemiólogo de la Fundación Osvaldo Cruz (Valery, 2020).

4. El Instituto del Corazón, en Brasil, analiza la relación entre COVID-19 e infartos y otras complicaciones cardíacas para evaluar los impactos de la enfermedad sobre ese órgano (Colucci, 2020).
A propósito de lo anterior, un análisis global de los datos sobre el perfil de las muertes ocurridas en el país en el año de 2020 revela indicios de subnotificación de los casos de COVID-19. Eso, debido al aumento de muertes por "causas naturales" en comparación con los años anteriores y, también, por el número de muertes por enfermedades respiratorias, como, por ejemplo, la SRAG (Síndrome Respiratoria Aguda Grave) ${ }^{5}$, cuyos números, en 2020, son muy superiores al promedio de los años anteriores, con una parte significativa de casos todavía no diagnosticados.

Por otro lado, hay inconsistencia entre los datos oficiales del Ministerio de Salud y las causas mortis indicadas en los certificados de defunción del país, estos últimos con número superior de muertes confirmadas o sospechas por COVID-19, en más de tres mil casos, tomándose por base la mayor fecha común de datos compilados y disponibles en línea ${ }^{6}$.

Detrás apenas de los Estados Unidos en los casos mundiales, el número total de muertes por COVID-19 en Brasil tiene algunas similitudes con los números de aquel país, pero lo que los aproximan no son los aspectos relacionados a las características geográficas o poblacionales de los países, sino aquellos relativos a la gestión de la pandemia, conducida, por ambos, sin políticas estrictas de aislamiento social, sin un adecuado acuerdo a nivel nacional de la política de salud e inadecuado enfrentamiento de los efectos sociales y económicos de la crisis para la protección de los más vulnerables.

5. Las páginas web más fiables para acompañar los datos de la pandemia en Brasil son: <https://painel.covid19br. org $>\mathrm{y}<$ https://bigdata-covid19.icict.fiocruz.br/>.

6. En 04.08.2020, los datos del Ministerio de Salud, compilados en la plataforma "Painel Covid-19" (https:// painel.covid19br.org/\#/brasil), indicaban 96.153 muertes, mientras la página de la transparencia de las notarías de registro civil indicaba el total de 99.394 muertes por sospecha o confirmación de la enfermedad (https://transparencia.registrocivil.org.br/especialcovid). Los datos de las notarías contienen un retraso de hasta diez días con relación a los datos diarios de muertes, debido al plazo legal para comunicación del evento, pero, a pesar de eso, sus números son mayores que las muertes oficiales. 
El papel de los alcaldes y de los gobernadores de Estado, en ese escenario, fue fundamental para mitigar los efectos perversos de la crisis. El modelo federativo, por tanto, se mostró relevante, inclusive, en Brasil, para evitar, al menos en parte, falencias de la gestión nacional de la crisis sanitaria y social y reveló los riesgos de la excesiva concentración de competencias en el ámbito de la Unión. También fue relevante la actuación del Congreso Nacional y del Tribunal Constitucional para evitar algunos abusos de poder o discriminación de minorías, aunque se considere que tal actuación no haya impedido efectos negativos graves de las políticas practicadas por el Poder Ejecutivo, lo que revela la insuficiencia de los mecanismos de control público y de los frenos y contrapesos existentes en el país, como se analizará.

Por otro lado, con un número superior de personas pobres y que viven en condiciones precarias de habitación y saneamiento básico, Brasil no tuvo un número de muertes mayor, pues, al contrario de lo que ocurre en los Estados Unidos, el país está dotado de un sistema público y universal de salud, que, a pesar de las falencias de la gestión nacional, está siendo capaz de ofrecer atendimiento básico y complejo, de modo totalmente gratuito, a las personas que se encuentran en el territorio nacional ${ }^{7}$.

Los problemas ocurridos en Brasil en el control de la pandemia, sin embargo, al contrario de lo informado por algunos medios de comunicación, no pueden ser considerados apenas "errores"8. Fueron, en

7. Hubo sobrecarga del SUS en algunas regiones, revelando falencias $\mathrm{y}$ desigualdades regionales anteriores a la pandemia, pero la falta de cotización o el desempleo no impiden el acceso de cualquier persona al sistema, lo que incluye inmigrantes y extranjeros de paso por el país.

8. Materia de la BBC News Brasil (Mota et all., 2020) relata los supuestos 09 "errores" de Brasil en el combate a la pandemia: "1: Ausencia de preparo para la pandemia", "2: No haber un plan nacional contra el coronavirus", "3: Bolsonaro haber minimizado la pandemia", "4: No hacerse testes masivos", "5: el aislamiento social insuficiente", "6: La publicidad de la cloroquina hizo mucha gente exponerse al vírus", "7: Los hospitales de campaña se tornaron un 'problema', "8: No se logró proteger a los indígenas", "9: No se logró proteger a los parte, acciones deliberadas, determinadas por un sistema económico creador de desigualdades, que, combinado con los déficits históricos de protección social y las preferencias políticas del dirigente de ocasión, impusieron una agenda "neoliberal", "antinacionalista" (a pesar de que se diga lo contrario) y "excluyente", todo eso por encima de la Constitución "Democrática" y "Social" vigente en el país y que prevé el respeto a los derechos fundamentales, así como regula el orden económico basado en la función social y ecológica de la propiedad.

El neoliberalismo aplicado a la gestión de los Estados, literalmente, mata ${ }^{9}$. Impone el brutalismo ${ }^{10}$ en la relación con las personas y con el planeta y está afectando, particularmente, a los más pobres, los trabajadores, los grupos étnicos y poblaciones tradicionales que, durante la pandemia, estuvieron aún más expuestos o desasistidos ${ }^{11}$. Tal conducta exigió la actuación de los otros poderes en la protección de los grupos más vulnerables, en particular, con relación a los indígenas, además de provocar denuncias en contra del presidente de la república, ante el Tribunal Penal Internacional de la Haya, por crímenes contra la humanidad.

Entre los denunciantes estuvieron representados los profesionales de salud, que ya suman más de 370 enfermeros ${ }^{12}$ y más

\section{más pobres".}

9. Según Max Neef, mata más que todos los ejércitos del mundo juntos (Florios, 2016).

10. Aquille Mbembe (2020) habla de "Brutalisme", como la marca de ese modelo económico.

11. Políticas capaces de ser catalogadas bajo criterios filosóficos, sociológicos o económicos, respectivamente, como tanatopolítica (Agamben, 2004), necropolítica (Mbembe, 2006) o economía del exterminio (Cárdenas, 2019), pues, por acción u omisión, revela la forma como los cuerpos ajenos son tratados, con mayor incidencia de violencia u omisión de cuidados sobre cuerpos negros, pobres, indígenas, LGBTQI, de ocupantes de territorios disputados por el capital o de portadores de modos de vida que el modelo económico quiere eliminar. En el caso de Brasil, nisiquiera los recursos destinados a políticas específicas previstos para tales grupos, especialmente, para los indígenas, fueron ejecutados.

12. El observatorio de enfermería recopila los datos sobre contaminación y muertes de estos profesionales de salud por la COVID-19 y los publica en su sitio web:<http://observatoriodaenfermagem.cofen.gov. $\mathrm{br} />$. 
de 210 médicos $^{13}$ fallecidos por COVID-19, revelando precarias condiciones de protección en el ambiente de trabajo. Brasil también es "poseedor del record" en número de mujeres embarazadas o puérperas víctimas de la enfermedad ${ }^{14}$, con más de 200 casos en total, lo que sirve de señal de alerta. Este dato (mortalidad materna) resulta clave para evaluar la calidad del sistema de salud de un país, de modo que tal número indica la probable mala gestión de los ejes específicos de atención médica básica durante la pandemia.

En el campo político, Brasil tiene problemas con el diseño institucional y el equilibrio de poderes, lo que dificulta el control democrático de los actos de un gobierno con perfil autocrático, así como el control recíproco entre los poderes, situación agravada, de un lado, por la cultura política autoritaria del país, incluido el mal interpretado papel constitucional de las fuerzas armadas en una democracia.

De otro lado, también dificulta la solución de los problemas del país su posición geopolítica históricamente subalterna $\mathrm{y}$, por ello, con poco esfuerzo de blindaje de los intereses estratégicos propios en contra de los efectos perversos del capitalismo global, aspecto que también necesita ser considerado al ser pensadas las soluciones para las crisis (sanitaria, social, política, económica y ambiental) que asolan el país, evidenciadas o agravadas por la pandemia, lo que se analizará a continuación.

\section{ANTECEDENTES DE LA CRISIS ACTUAL Y SUS ORÍGENES - EL CONSTITUCIONALISMO NEOLIBERAL FINANCIERO SE IMPONE POR MEDIO DE REFORMAS}

13. No hay datos seguros sobre muertes de médicos por COVID-19 en Brasil, pero noticia publicada en la página web del Sindicato de Médicos de São Paulo indicaba la ocurrencia de 217 casos, hasta el 07.08.2020. Recuperado de: <https://simesp.org.br/noticiassimesp/ numero-de-medicos-mortos-por-covi-19-chega-a-217no-dia-nacional-de-luta-e-luto/>

14. Más de $70 \%$ de los casos de muertes de puérperas y embarazadas por COVID-19 en el mundo ocurrieron en Brasil.

\section{CONSTITUCIONALES Y LEGALES Y DE GOBIERNOS AUTOCRÁTICOS}

Las crisis por las cuales pasa actualmente Brasil son consecuencia de un proceso político-económico que tiene origen en la profundización del neoliberalismo financiero, el mismo modelo económico que provocó la crisis financiera mundial de 2008, pero que, a partir de ahí, no cambió su ruta de expansión, sino, al contrario, está imponiendo su hegemonía en América Latina, está por detrás de los llamados "golpes políticos" en la región y se refleja, en el caso de Brasil, en una serie de políticas regresivas de derechos, en la superexplotación ambiental y en el debilitamiento del capital productivo local, a fin de favorecer el capital financiero e internacional; lo que ocurrió, especialmente, a partir del impeachment de la presidenta Dilma Roussef.

Tal modelo político-económico es incompatible con el fortalecimiento de la soberanía nacional, la industrialización, la inversión en ciencia y tecnología, la generación de empleos dignos y la efectividad de los derechos económicos, sociales, culturales y ambientales (DESCA).

Apenas para mencionar algunos cambios ocurridos en Brasil, a partir de 2016, que fragilizaron la fiscalidad, el patrimonio público y privado nacionales y los derechos ciudadanos, podemos citar: (i) la aprobación de la Enmienda Constitucional 95/2016, que congeló, por veinte años, los gastos públicos con políticas sociales; (ii) la privatización de la reserva de petróleo denominada "pré-sal", responsable por el "fondo social" creado para financiar salud y educación en el país; (iii) el perdón (reducción significativa) de débitos tributarios de grandes bancos privados, en 2017, a pesar de ser el sector con más rentabilidad en el país; (iv) las reformas regresivas en el campo laboral, en el sistema de pensiones y en el orden económico, por medio de leyes o reformas constitucionales, como las leyes 13467/2017 y 13874/2019, la Enmienda Constitucional 103/2019 $\mathrm{y}$ diversas medidas provisorias $(\mathrm{MP})^{15}$

15. Especie de decretos presidenciales expedidos en casos de urgencia y relevancia, con fuerza de ley, 
restrictivas de derechos, inclusive, durante la pandemia.

Sin embargo, en el período no ocurrieron únicamente cambios normativos. También sucedieron cambios de postura del gobierno con relación a políticas públicas de protección a los DESCA, de fomento a la política cultural, de financiación de la ciencia y tecnología, de implementación del acceso a la tierra, de protección a las comunidades indígenas y afrodescendientes, de preservación ambiental y de fomento a las políticas de inclusión de género. Ese cambio se dio, inclusive, en el campo de las relaciones internacionales, con el inédito alineamiento de Brasil, en el ámbito de la ONU, a países defensores de agendas conservadoras o negacionistas de evidencias científicas y de conquistas históricas en los campos antes mencionados.

Compatible con esa postura, Brasil suprimió de la estructura gubernamental los Ministerios de Trabajo, de Cultura y de Industria y Comercio y, en el ámbito del Ministerio de Economía, trabaja prevalentemente para el fortalecimiento de la agenda financiera del país y para la privatización de empresas estatales. No hay incentivo a la industria nacional y se opera el desmonte de órganos de fomento a la industria cultural, como la Agencia Nacional de Cine, por medio de recorte de presupuesto o censura a películas relacionadas con temas de la "guerra cultural" conservadora vigente en el país, como las cuestiones políticas y de género.

En el campo ambiental y de la ciencia y tecnología, se boicotean acciones de fiscalización ambiental de los órganos de policía, de investigación o de protección ambiental, como el IBAMA (Instituto Brasileiro de Meio Ambiente e dos Recursos Naturais Renováveis), el ICMBio (Instituto Chico Mendes de Conservação da Biodiversidade) y el INPE (Instituto Nacional de Pesquisas Espaciais). Los órganos de

relativos a materias sujetas a la reserva legal, pero con validez temporal y posibilidad de ratificación o no por el Congreso. protección a minorías, como la FUNAI (Fundação Nacional do Índio), responsable por la política indigenista, y la Fundação Cultural Palmares, responsable por la protección y promoción de los derechos de las comunidades afrodescendientes, a su vez, están haciendo políticas o declaraciones contrarias a los grupos que deberían proteger, lo que también es motivo de judicialización de la política.

El Ministerio de Educación promovió recorte de recursos para la enseñanza e investigación y el Ministerio de Salud eliminó programas de atención primaria a la salud, como el Programa "Mais Médicos", que contrataba profesionales de salud, incluidos extranjeros, para actuar en ciudades con déficit de profesionales brasileños, especialmente, ciudades pequeñas o lejanas del Centro-Sur del país, además de promover recortes de personal en el Programa de Salud de la Familia y en los gastos con el SUS.

Hubo eliminación de consejos ciudadanos integrantes de la administración pública federal y restricción de la participación popular en los consejos remanentes, responsables por la elaboración o coordinación de políticas públicas específicas, como la política ambiental, de salud, de educación, de seguridad pública, de derechos humanos y de igualdad racial. Tal cuestión fue objeto de judicialización ante el STF, que mitigó el acto presidencial en cuánto a la eliminación de consejos previstos en ley, pero no evitó su vaciamiento. Las políticas de acceso a la información también sufrieron restricciones y fueron objeto de demanda ante el STF.

En lo que se refiere a la gestión de la política de salud, el Ministerio de Salud fue ocupado, durante la pandemia ${ }^{16}$, por un ministro interino, militar de carrera, que retiró de cargos estratégicos los especialistas que actuaban en el órgano, nombrando militares en su lugar. Se realizó

16. El General Eduardo Pazuello fue nombrado el 15.05.2020 y sigue ocupando el cargo. Según información de periódicos, por lo menos 13 militares fueron nombrados por él para ocupar cargos de gestión en su Ministerio. 
la producción en exceso de medicamento ineficaz (hidroxicloroquina), mientras hubo insuficiente provisión de otros esenciales para el tratamiento de la COVID-19, como los usados en las $\mathrm{UCIs}^{17}$, lo que revela una actuación del Ministerio sin base en opiniones técnicas de expertos y epidemiólogos, contrariando recomendaciones de la CIDH y del CDESC, en sus resoluciones sobre la pandemia y la Observación General № 25 del CDESC sobre el derecho humano a que las políticas públicas sean basadas en evidencias de la ciencia.

La militarización del gobierno ${ }^{18}$, así como la discontinuidad de políticas públicas que protegen los derechos ciudadanos, el medio ambiente y las minorías, concomitante al desmonte de los órganos responsables por elaborar y ejecutar las políticas relacionadas a esas áreas, por tanto, no son apenas "errores", sino acción deliberada que revela un proyecto político contrario al fortalecimiento de una democracia constitucional, participativa e igualitaria.

La literatura reciente con respeto a cómo las democracias mueren, demuestra que las prácticas vigentes en Brasil no son aleatorias.

Levitsky y Ziblatt (s.f., posición 469/492) destacan, en su análisis, el papel central de la conducta del dirigente autoritario para la muerte de las democracias contemporáneas. Los autores llaman la atención sobre cuatro comportamientos que se repiten en distintos escenarios, lo que pasa en Brasil en el actual gobierno: "1. Rechazo a las reglas democráticas del juego (u compromiso débil con ellas); 2. Negación de la legitimidad de los oponentes políticos; 3. Tolerancia u estímulo a la violencia; 4. Propensión a

17. Desde el mes de mayo noticias variadas indican la falta de medicamentos usados en UCIs en Brasil (G1, 2020). Recuperado de: <https://g1.globo.com/ jornal-nacional/noticia/2020/06/25/estoque-demedicamentos-usados-em-utis-esta-zerado-em-21estados-e-no-df-diz-levantamento.ghtml>.

18. Son más de 6.000 cargos ocupados por militares, conforme apuración del Tribunal de Cuentas de la Unión (Camarotto, 2020), incluidos 09 Ministerios. La militarización también atinge la educación, con la expansión de colegios militarizados (escuelas cívicomilitares) en todo el país. restringir libertades civiles de oponentes, inclusive los medios de comunicación".

Ginsburg y Huq (2018, p.115-116), también preocupados con el tema, revelan que las democracias actuales no necesariamente mueren abruptamente o por golpes militares, como ocurría en el siglo pasado. Hay estrategias que llevan al mismo resultado, por medio de la "erosión" de esa forma de gobierno. Eso se da, por ejemplo, apelando a los temas de seguridad nacional para restringir derechos; con la eliminación de opositores en las instituciones del Estado, como en tribunales o fuerzas armadas (purgas, destituciones, intimidaciones, etc); por medio de ataques a la sociedad civil y a la prensa por oponerse a "valores" defendidos por el gobierno; por el debilitamiento de la autoridad de la ciencia, con la falta de fondos o la politización de los debates científicos, a fin de favorecer la prevalencia de una agenda negacionista o anti derechos humanos:

The use of democratic, constitutional forms to achieve antidemocratic ends is nothing new. But the anti-democrat's tool kit has become increasingly sophisticated of late. A careful review of available case studies suggests how a rough playbook for would-be illiberal democrats works in practice. First, run a populist platform, in which the majority is portrayed as victimized and the old order elitist. Such was the strategy of, for example, Orbán in Hungary and Erdoğan in Turkey. Emphasize threats to national security or the purity of the homeland. Next, find ways to undermine opponents in state institutions, such as the judiciary or military, through a combination of appointments, purges, patronage, and even intimidation. Perhaps use the courts to repress criticism via libel suits or the like. Critically, do not forget to manipulate the electoral institutions so as to ensure that future competition is limited. Then, attack civil society as foreign-funded elite carriers of globalist ideas that do not comport with national values. Ensure that the free media are intimidated, or diluted, so as not to provide an independent check: This is particularly 
easy to do in an era of privatization in which the press can literally be bought. Finally, undermine academic authority through underfunding or outright politicization. The effect of these measures is cumulative; even if one alone is insufficient to raise concerns about democratic erosion, when sufficiently numerous, they should be viewed with alarm. (Ginsburg y Huq, 2018, p.115-116).

Observando los cambios mencionados, llegamos a la conclusión de que, si para la expansión global de los mercados, a partir del período posguerras del siglo pasado, la democracia liberal parece haber sido el modelo elegido e incentivado por las potencias capitalistas, actualmente, para profundizar la agenda financiera, la importancia de ese modelo está siendo relativizada. Esto, debido a la sistemática imposición de recortes de gastos públicos relacionados a las políticas sociales protectoras de los derechos fundamentales y la violación a los principios de no regresividad y de aplicación de lo máximo de recursos disponibles.

Wolfgang Streeck (2017), al examinar críticamente el modelo capitalista actual, indica que el neoliberalismo financiero opera una completa inversión de paradigmas con relación a los modelos de Constitucionalismo Liberal y Social y, a partir de él, se pasa a pensar la misión del Estado como siendo la de favorecer y garantizar el capital financiero e internacional en las transacciones internacionales.

Streeck (2017, p. 154) describe la aplicación del modelo a partir de lo que ocurre en Europa, pero los mismos paradigmas están presentes en el modelo aplicado en América Latina, como lo destacado por Freitas (2020). En ese sentido, hay predominancia de: (i) lo "internacional", con relación a lo "nacional"; (ii) los "inversores", con relación a los "ciudadanos"; (iii) las "reclamaciones contractuales", con relación a los "derechos civiles"; (iv) los "acreedores", con relación a los "votantes"; (v) las "subastas bursátiles (continuas)", con relación a las "elecciones (periódicas)", y (vi) el "servicio de la deuda", con relación a los "servicios públicos".

No es casual, por tanto, que los Estados en el mundo más afectados por la pandemia no fueron, necesariamente, los pequeños y más pobres, sino, exactamente, aquellos cuyos dirigentes de ocasión eran defensores del ultraliberalismo financiero, como es el caso de Estados Unidos, Brasil, Inglaterra e Italia. Tampoco es casual que la concentración de riqueza haya seguido su curso de expansión durante la pandemia y que los bancos sigan siendo los principales beneficiados por las políticas económicas en el país.

Pero la situación es todavía más grave cuando ese modelo alcanza y afecta a América Latina, pues, además de fragilizar los derechos ciudadanos, históricamente débiles en la región, también compromete el futuro de los países por inviabilizar proyectos autónomos de desarrollo nacional o regional. Eso se da, especialmente, ante la imposición, en la división internacional del trabajo, de una agenda de producción de bienes primarios, con alto impacto ambiental y bajo valor agregado que, además, perjudica la soberanía y la seguridad nacional con relación al suministro de bienes manufacturados, inclusive los esenciales para el tratamiento de la COVID-19, como dispositivos médicos, medicamentos $\mathrm{y}$ equipos de protección individual para los trabajadores del sector de salud (Setipa, 2020).

Por lo expuesto, la pandemia no es causa de la crisis económica actual, sino consecuencia del modelo económico global, que genera pérdida de hábitats y de biodiversidad $\mathrm{y}$, por tanto, desequilibrio ambiental, con aumento de los riesgos de enfermedades transmitidas por virus. También provoca el aumento de la pobreza y, con ello, el aumento o retorno de enfermedades evitables relacionadas a problemas estructurales (vivienda precaria; falta de acceso al agua potable y a saneamiento básico), que necesitan ser superados también de modo estructural. Esos mismos problemas también están 
en la raíz del aumento de las muertes por COVID-19 en zonas más pobres del país.

Los impactos de la crisis, por tanto, serán mucho más fuertes si no se cambia el modelo de desarrollo económico, social y ambiental, que está en su origen, especialmente, por la necesidad de evitarse nuevas pandemias, de reducir las desigualdades sociales y de promover la protección ambiental y el acceso a derechos, bienes y servicios básicos, lo que no se ve en el horizonte político de corto plazo de la región, que sigue sometida a intereses geopolíticos y neocoloniales contrarios a los intereses y necesidades de su pueblo, lo que se necesita superar.

\section{AUTORITARISMO, EXCLUSIÓN DE LAS MINORÍAS, SUBALTERNIDAD Y DESEQUILIBRIO DE PODERES - LA HERENCIA COLONIAL, LOS ESCOMBROS DE LA DICTADURA Y LA INCOMPLETA TRANSICIÓN DEMOCRÁTICA DE BRASIL - DESAFÍOS URGENTES A SUPERAR}

Como ha destacado Fernandes (2005), la sociedad brasileña, desde la época colonial, se caracterizó por el aislamiento de su entorno regional, la dependencia de intereses externos y las desigualdades extremas entre los grupos que componían su población. Tales grupos (blancos terratenientes y sus descendientes, afrodescendientes e indígenas) son, hasta hoy, la base de las clases sociales existentes en el país, las cuales espejan la desigualdad social y el racismo estructural todavía vigentes (Freitas, 2020).

La forma "señorial" de la propiedad de la tierra, como lo resaltan Souza (2017) y Comparato (2017), contribuyó al sometimiento abusivo de la población negra e indígena a los colonizadores, pues, además de la concentración de la propiedad, los dueños de la tierra tenían poderes absolutos en los límites de su posesión, ante la ausencia de instituciones de mediación política, las cuales tardaron a ser implantadas en Brasil y nunca fueron verdaderamente permeables a los intereses del pueblo, especialmente, de los grupos étnica y socialmente excluidos.
Russel-Wood (1998) registra que la colonia de Brasil era vista por Portugal apenas como una fuente de riquezas (especialmente, para cobro de impuestos y fornecimiento de materias primas). La metrópoli, además, ejercía una administración excesivamente centralizadora. Brasil no podía procesar su riqueza y sufría una restricción total a la implementación de manufacturas en su territorio.

Por otro lado, la corona también desarrollaba una política de "imperialismo cultural" (Russel-Wood, 1998) y sistemáticamente negaba la autorización para creación de universidades en el territorio brasileño, prohibía la prensa, cerraba las imprentas que intentaban instalarse y censuraba previamente las publicaciones destinadas a circular en el país, lo que marcó una tendencia anti-ilustración y de ausencia de prioridad de inversión en educación pública (Freitas, 2020). Lo anterior explica, hasta hoy, los constantes retrocesos en los campos de la ciencia y de la educación, así como la persecución política a educadores comprometidos con la educación popular y la escuela pública ${ }^{19}$.

El acceso a la tierra era restringido y lo siguió siendo tras la independencia, debido a la Ley de Tierras de 1850 (Ley 601,1850) ${ }^{20}$, que determinaba que la compra era el único modo de su adquisición, impidiendo el acceso a ella por parte de los antiguos esclavos, quienes no fueron beneficiados por ninguna política compensatoria para la superación de su condición social, al contrario de lo que ocurrió con los inmigrantes blancos, traídos de Europa como parte de una

19. Se cita, a título de ejemplo, Anísio Teixeira, Paulo Freire, Florestan Fernandes y Darcy Ribeiro, internacionalmente reconocidos por sus obras en el campo de la sociología, antropología y educación y perseguidos o banidos por regímenes autoritarios del país, inclusive, en el presente.

20. Además de dividir las tierras de la colonia entre las familias blancas indicadas por el colonizador (sistema de capitanías hereditarias), con el fracaso de tal forma de ocupación, las políticas de tierras en el Brasil colonial favorecieron la acumulación de tierras por los blancos, al no permitir la distribución de tierras a los grupos económicamente excluidos, ya que la Ley de Tierras de 1850 exigía su "compra" como forma exclusiva de adquisición. 
política "eugenista" de blanqueamiento de la población y que recibieron tierras para cultivo, otro factor que explica el perfil racial de la pobreza y de la desigualdad en Brasil, donde los indígenas siguen siendo objeto de exterminio, y los afrodescendientes, víctimas preferentes del racismo y de la violencia institucionalizados ${ }^{21}$.

El movimiento que determinó el fin de la monarquía tampoco tuvo participación popular. Tal movimiento se aceleró con el fin de la esclavitud legalizada, en 1888, y se dio mediante un golpe de Estado militar, con apoyo oligárquico, que expulsó la familia real del país, sin promover cambios significativos en la estructura social o en la relación de sumisión del país a intereses externos, que, en aquel entonces, eran, prevalentemente, ingleses.

Los hechos históricos mencionados influencian la cultura jurídica y política de Brasil hasta hoy. Fernandes (2005) destaca los rasgos de la relación entre "derechos humanos y la cultura jurídica brasileña", o cómo se da, según él, la "producción legal de la ilegalidad", al afirmar que:

Estados que apresentem uma cultura jurídica com esses dois traços (o isolacionismo e o desrespeito aos direitos humanos), quando integrem tratados de direitos humanos, tenderão a reduzir a efetividade desses tratados, mesmo quando as Constituições nacionais com eles se harmonizem (nesse caso, também o direito constitucional terá pouca efetividade). Poderá ocorrer que a própria eficácia formal desses tratados seja negada; ou que sejam interpretados de forma a gerar efeitos contrários à sua finalidade (Fernandes, 2005, p. 9).

21. El mapa del encarcelamiento revela que el $60 \%$ de la población carcelaria de Brasil está compuesta por jóvenes mestizos y negros, y que cerca de $2 / 3$ de las muertes violentas, causadas, incluso, por la policía, son de jóvenes negros. Ver el mapa del encarcelamiento de Brasil (Presidencia de la República. Secretaria Geral, 2015 b) y el índice de vulnerabilidad juvenil a la violencia y la desigualdad racial (Presidencia de la República. Secretaria Geral, 2015a). Tales índices se encuentran en grado de empeoramento con las restricciones de las políticas sociales y la persecución ideológica a las minorías.
Eso explica la facilidad con que políticas regresivas se instalan en el país y denuncia la urgencia de promover cambios culturales en el sentido de fortalecer el constitucionalismo de perfil transformador y de promover la efectividad de la democracia y de la aplicación de los derechos humanos.

Las resistencias a los avances democráticos también marcaron el proceso constituyente. Freitas (2020) destaca que la apertura del régimen militar (o civil-militar ${ }^{22}$ ) fue gradual, pero sin propiciar un efectivo proceso de transición, especialmente, por la ausencia de punición de los abusos cometidos durante la dictadura. Tal modelo de apertura restringió la discusión política acerca del papel de las fuerzas armadas en un régimen democrático, favoreciendo la presencia de la sombra del régimen autoritario durante el proceso constituyente y la tolerancia de sus defensores hasta los días de hoy.

La transición política limitada tras el fin de la dictadura dio lugar a la interrupción de diversos procesos relevantes para la consolidación de la democracia participativa e igualitaria en el país. En primer lugar, a pesar de la intensa movilización social por elecciones directas para presidente de la república (movimiento "Directas Ya"), el Congreso Nacional no aprobó esa propuesta ${ }^{23}$, siendo realizadas, de modo indirecto, las primeras elecciones presidenciales, en 1985.

El candidato elegido para el cargo de presidente (Tancredo Neves) se enfermó y murió antes de la posesión. Su sucesor, José Sarney, político de perfil conservador $\mathrm{y}$ vinculado al grupo político que antes apoyaba el régimen militar, mantuvo el compromiso de cambiar la Constitución,

22. Hoy se dice que la dictadura brasileña (Silva Filho, 2011), así como otras del Cono Sur, fueron dictaduras civiles-militares, y que recibieron apoyo de diversas empresas nacionales y multinacionales instaladas en los respectivos países. Elio Gaspari (2017) menciona la colaboración material de empresas nacionales y multinacionales como Ford, Volkswagen, Ultragaz y Supergel con los aparatos de la represión militar, con el incentivo de la Federación de las Industrias de São Paulo.

23. Enmienda Dante de Oliveira, propuesta presentada por el Diputado Federal de mismo nombre. Las elecciones indirectas fueron realizadas por el Congreso Nacional. 
pero, conforme acuerdo político previo, convocó una Asamblea Constituyente Congresual, que fue aprobada por la Enmienda Constitucional No 26, de 1985, norma que también amnistió a los militares por los crímenes de la dictadura.

Sarmento (2009, pp. 9-10) registra que:

A fórmula adotada foi objeto de fortes críticas entre os setores mais progressistas da sociedade, que preferiam a convocação de uma Assembleia Constituinte exclusiva, que não cumulasse os seus trabalhos àqueles da legislatura ordinária, e que se dissolvesse assim que concluída a sua obra. Contestava-se, ademais, a presença, na Assembleia Constituinte, dos senadores biônicos, eleitos indiretamente em 1982, cujos mandatos expirar-seiam apenas em 1990. A nomeação da Comissão de "notáveis" presidida por Afonso Arinos também foi objeto de críticas de setores à esquerda, que não aceitavam o protagonismo do Presidente da República na definição da agenda da Constituinte. 0 modelo adotado parece ter resultado de um compromisso com as forças do regime autoritário, travado ainda antes do óbito de Tancredo Neves, pois estas temiam que uma Assembleia Constituinte exclusiva pudesse resvalar para o "radicalismo", ou até para o "revanchismo" contra os militares - leia-se, a sua responsabilização pelas violações de direitos humanos perpetradas durante a ditadura, como já estava então ocorrendo na Argentina (Sarmento, 2009, pp. 9-10).

D’Araújo (2012) relata que la influencia política militar se mantuvo intocada y esa categoría actuaba "como veto player siempre que se intentó volver a discutir o revisar la Ley de Amnistía de 1979", lo que también ayuda a explicar la influencia militar en la política y la ambigua interpretación que se da al artículo 142 de la Constitución de Brasil, que pretende legitimar la narrativa conservadora que atribuye a las fuerzas armadas un papel moderador en caso de crisis institucionales, poder este incompatible con una democracia constitucional.

La ausencia de una Asamblea Constituyente exclusiva, por otro lado, también dificultó la realización de cambios en la estructura de acceso al poder, especialmente, al poder Legislativo, ya que las mismas fuerzas políticas interesadas en la materia fueron las responsables por crear las reglas del juego político-electoral. En ese sentido, la afirmación genérica de Gargarella (2014) de que las nuevas constituciones latinoamericanas tienen "dos almas", por tener una parte orgánica conservadora y una parte dogmática con amplio catálogo de derechos, se aplica bien al caso brasileño, aunque se discuta si esa conclusión es válida para otros países de la región.

Debido, todavía, al papel doble de la Asamblea Constituyente, el STF, era el órgano responsable por el control de constitucionalidad de los actos practicados por el congreso en sus funciones ordinarias $\mathrm{y}$, en calidad de actor político, terminó por ejercer influencia en el mantenimiento de su propia estructura y composición, lo que se logró tanto en la Comisión Afonso Arinos ${ }^{24}$ como en el texto final de la Constitución ${ }^{25}$.

En ese sentido, todas las propuestas de creación de una Corte Constitucional exclusiva, de instituir mandatos para los miembros de la Corte, de alterar la forma de nombramiento de sus miembros, entre otras, fueron rechazadas. Hubo un aumento de la competencia de la Corte en reformas sucesivas, sin alteración de su estructura, lo que contribuyó para el aumento del desequilibrio de poderes (Freitas \& Bustamante, 2017).

24. Comisión de notables designada por el presidente elegido y que elaboró un anteproyecto constitucional. Ese proyecto no fue formalmente considerado por la asamblea constituyente, aunque pudo haber influenciado los debates y propuestas.

25. Koerner y Freitas (2013) indican que se consideró la creación de un Tribunal Constitucional propuesta por el constitucionalista José Afonso da Silva, pero la comisión, al final, atendió a las "demandas y presiones" de los magistrados del STF. 
Las medidas de participación popular implementadas fueron limitadas y, además, son poco estimuladas. Los requisitos exigidos para aprobar leyes de iniciativa popular son muy rigurosos $\mathrm{y}$, cuando son presentados, no reciben prioridad en la agenda del parlamento, siendo pocos los casos de leyes aprobadas a partir de ese mecanismo. También es rara la realización de plebiscitos y de referendos.

Codato (2005, p.101) concluye que el autoritarismo brasileño es compatible con la agenda neoliberal, claramente antidemocrática, motivo por el cual la participación popular tampoco avanzó durante los primeros gobiernos elegidos después del fin de la dictadura, cuando se dio el auge de la primera ola de reformas liberalizadoras en la región.

Los problemas de diseño institucional no fueron corregidos por las posteriores reformas políticas y electorales, de modo que no se logró mejorar la legitimidad del Congreso, cuyo sistema de elecciones proporcionales, con alianzas de bloques de partidos políticos, termina por conformar un organismo en el cual, casi la totalidad de los diputados son elegidos sin votos propios ${ }^{26}$, lo que favorece el poder económico, que puede financiar muchos candidatos de fachada para elegir a políticos de partidos tradicionales.

Además, no hay límites para reelección, cuotas para afrodescendientes o minorías étnicas, régimen de inhabilidades para ocupación de cargos públicos en el poder ejecutivo durante el mandato, impedimentos para votar leyes conflictivas con sus intereses personales, para contratar con el poder público o para nombramiento de parientes para ocupar cargos públicos, avances que, por ejemplo, Colombia logró aprobar o que puso en la agenda del debate público.

El aumento de la competencia del STF, especialmente para decidir acciones de control concentrado de constitucionalidad

26. En las últimas elecciones apenas 27 de los 513 diputados elegidos tuvieron votos propios suficientes para elegerse, lo que representa $5,26 \%$ de lo total de miembros de la Cámara (Vivas, 2018). y para emitir jurisprudencia con carácter vinculante, amplió su influencia sobre los otros tribunales del país y sobre la agenda política. Por otro lado, el poder individual de sus magistrados para emitir decisiones provisionales ${ }^{27}$, surgido en los últimos años por razones pragmáticas, fragiliza la competencia de la sala plena, lo que es motivo de preocupación en el momento presente, cuando será nombrado un nuevo integrante de la Corte. Esa preocupación está relacionada al papel esencial que tiene la Corte en la protección de los derechos fundamentales y en el control constitucional de los actos de los agentes públicos, lo que puede ser afectado negativamente si un magistrado individualmente practicar algún acto que pueda generar bloqueo del Tribunal Pleno $^{28}$.

La preocupación anterior está relacionada a la competencia exclusiva del presidente de la república para nombrar funcionarios de cargos relevantes, a ejemplo de los Magistrados del STF y del Procurador General de la Nación, dos órganos centrales en el control de la agenda política y ciudadana. Es ahí donde se revela la cara principal del hiperpresidencialismo de Brasil: el poder de nombrar, con amplio margen de discrecionalidad, una gama enorme de funcionarios públicos $y$, por otro lado, de influenciar en el perfil o en la gestión de diversos órganos que cumplen funciones esenciales en la administración pública, lo que puede empeorar se aprobada reforma administrativa que fragiliza, todavía más, las carreras del funcionalismo público.

Cuando la función presidencial es ejercida de modo abusivo, las interferencias indebidas son mayores, especialmente, en órganos

27. Los magistrados del STF deciden, individualmente, los pedidos relativos a las tutelas provisionales $\mathrm{y}$ someten el proceso a la sala plena para ratificar o no el orden provisional. No hay plazo para tal apreciación por la Sala Plena, de modo que una decisión "monocrática" pude hacer efecto durante mucho tiempo.

28. Estudiosos del STF (Arguelhes \& Ribeiro, 2018, p. 21) apuntan por lo menos 03 formas de un magistrado individualmente bloquear la sala plena: 1) no liberar el ponente el caso para decisión plenaria; 2) uno de los miembros de la Corte pedir vista del caso; y 3) el presidente del Tribunal no incluir el proceso en la agenda para deliberación plenaria. 
que no tienen garantías funcionales ${ }^{29}$. Aun así, no es inusual la burla de las mismas garantías. Hay poco blindaje de órganos que hacen el control de los gastos públicos (como contralorías y tribunal de cuentas), de los que fiscalizan actividades económicas (caso de las agencias reguladoras) o que tienen la misión de garantizar los derechos fundamentales (policías administrativas, defensorías públicas, auditoría fiscal del trabajo) lo que facilita su intencional vaciamiento, especialmente por medio de cortes presupuestarios y de personal, mecanismos típicos de erosión de las democracias contemporáneas, como advierten Ginsburg y Huq (2018).

Cabe destacar, por otro lado, que ni siquiera el cargo de presidente de la república goza de suficientes garantías democráticas en Brasil. Hay una enorme fragilidad relacionada a la preservación del mandato electivo, pues el juicio político presidencial no ofrece garantías sustantivas suficientes para que el acusado pueda defenderse de los crímenes que le fueron atribuidos y, en los últimos casos ocurridos en el país, se observó que el factor preponderante para la separación del presidente de su cargo, no fue la gravedad de los actos practicados, sino la pérdida de apoyo de la mayoría del Congreso.

Además, las reglas de sucesión presidencial en caso de impeachment tampoco ofrecen blindaje al mandato electivo, ya que no se convocan nuevas elecciones, ni hay reglas de transición para el ejercicio del cargo presidencial por el sucesor. En ese sentido, ni siquiera durante el trámite del juicio político hay límites de competencia para el presidente interino, lo que le permite tomar decisiones que crean hechos consumados, como sucedió, por ejemplo, durante la tramitación del juicio político de la presidenta Dilma Roussef, que no renunció al cargo y que por tanto, podría volver a ocuparlo, a diferencia del caso anterior (impeachment del presidente Collor de Mello).

29. Como, por ejemplo, autonomía administrativa, mandato electivo de sus dirigentes, organización y competencia fijada en ley.
La pandemia reveló, por tanto, que la lección de casa relativa a la transición para la democracia en Brasil no fue suficientemente cumplida por la Constitución de 1988 y, ante un gobierno autocrático, el mal diseño de la casa de máquinas del Estado brasileño fragiliza $y$ puede victimar las propias instituciones que no se dejaron reformar, lo que se debe evitar.

Así las cosas, se necesita pensar en reformas políticas para perfeccionar los diseños institucionales de los tres poderes, pero, también, para mejorar el control sobre las prácticas institucionales, con el fin de ampliar los mecanismos de transparencia, confianza institucional y participación ciudadanas. En tiempos autoritarios, las auto reformas pueden ser la salida, especialmente, para el parlamento y el STF, en caso de que se quiera proteger su institucionalidad democrática.

Además, su actuación efectiva exige la comprensión de que la protección de los derechos y de los servicios esenciales no se da apenas por medio de leyes sustantivas, sino por su efectiva implementación. Para tal fin, además de exigirse que los planes de acción de los gobiernos retiren los derechos del papel, es necesario instituir y respetar las garantías de los derechos fundamentales (libertad de asociación y de expresión; acceso a la justicia y la información; debido proceso administrativo y legal, etc) y promover el fortalecimiento de los órganos responsables por fiscalizarlos e implementarlos.

En ese sentido, se destacarán ejemplos de cómo se dio, en Brasil, la protección de los derechos fundamentales y sus garantías durante la pandemia y los problemas enfrentados para su efectividad, lo que será examinado en el marco de la protección de la democracia sustantiva y participativa, ante un hiperpresidencialismo que se ejerce de modo "abusivo"30.

30. Landau (2013) conceptúa el constitucionalismo abusivo como el uso de mecanismos de cambio constitucional (enmienda o reemplazo constitucional) para socavar la democracia, aquí se demuestra como la falta de institución de mecanismos de protección a los servicios públicos que garanten la implementación de 
4. LA RESISTENCIA DEMOCRÁTICA Y LAS LECCIONES DE LA CRISIS - EL PAPEL DEL CONGRESO Y DEL TRIBUNAL CONSTITUCIONAL ANTE UN "HIPERPRESIDENCIALISMO ABUSIVO" - ELEMENTOS PARA ENTENDER LOS DESAFÍOS DE LA PROTECCIÓN DE LOS DERECHOS FUNDAMENTALES Y DE LA DEMOCRACIA PARTICIPATIVA Y SUSTANTIVA EN BRASIL

La falta de coordinación del Poder Ejecutivo Nacional entre sus ministerios y entre los órganos ejecutivos de deferentes niveles ocasionó una sobrecarga en los otros poderes cuanto a las funciones de control o de implementación de políticas públicas para contener las crisis ocasionadas por la pandemia, lo que no se dio no solo a causa de omisiones del poder ejecutivo, sino, también, por las políticas discriminatorias o abusivas, con efectos negativos, especialmente, para los más vulnerables.

Para examinar algunas de las más importantes medidas tomadas por los tres poderes y comprender como actuaron los mecanismos de frenos y contrapesos en el enfrentamiento de la pandemia serán mencionadas decisiones relevantes relacionadas a los siguientes aspectos: a) Medidas de enfrentamiento económico y sanitario de la pandemia; b) Medidas de combate al racismo estructural o de protección a minorías vulnerables; c) Medidas de protección a los derechos fundamentales y sus garantías.

En lo que se refiere al Poder Judicial, la coordinación de las acciones fue más efectiva, pues, además de la existencia de un órgano nacional de autogobierno (el Consejo Nacional de Justicia - CNJ), cada rama de la Justicia tiene sus proprios consejos o órganos

derechos permiten que la competencia administrativa del presidente sea usada, de modo abusivo, en contra de las funciones que esos mismos órganos deben cumplir, de modo a socavar la democracia igualitaria y participativa. de control interno, que establecieron las medidas administrativas de aislamiento social y atendimiento al público. Además, fue facilitada, por el CNJ, una plataforma virtual para celebración de los juicios en todo el país.

Hay poco perjuicio en la tramitación de los procesos ya decididos en primer grado, pues los expedientes judiciales en Brasil, especialmente, en el ámbito laboral, son, en su casi totalidad, electrónicos. El perjuicio es mayor con relación a los actos que necesitan ser cumplidos presencialmente y con relación a la celebración de juicios virtuales de las partes o testigos que no tienen acceso a los medios electrónicos necesarios. En ese sentido, la pandemia reveló la brecha digital existente en el país, con limitado acceso a la internet por los más pobres y con escasos servicios de internet pública.

Para conocer las medidas de los principales tribunales se puede visitar las páginas web con repositorios de jurisprudencia y de decisiones administrativas sobre la COVID-1931. Algunas de las decisiones más importantes del STF serán mencionadas abajo, de modo integrado con las medidas de los demás poderes, conforme los temas seleccionados para análisis. Se dará destaque a las decisiones proferidas en sede de control concentrado de constitucionalidad, por su importancia $\mathrm{y}$ destaque entre las muchas decisiones proferidas $^{32}$.

31. Principales páginas web del Poder Judicial con informaciones sobre el control de la pandemia: CNJ: $<$ https://www.cnj.jus.br/sistema-carcerario/covid-19>; STJ: <http://www.stj.jus.br/sites/portalp/Paginas/ STJ-no-Combate-ao-Coronavirus.aspx>; TST: <http:// www.tst.jus.br/coronavirus $>$ y <https://sites.google. com/view/covidleistrabalhistas/>; STF: <https:// transparencia.stf.jus.br/extensions/app_processo_ covid19/index.html>.

32. El STF de Brasil, con su competencia originaria y revisora, de control difuso y concentrado de constitucionalidad, puede recibir 52 tipos de acciones. Sobre la COVID-19, más de 5.000 decisiones fueron proferidas, siendo más de 3.000 habeas corpus. Entre las decisiones más importantes, destacadas por la propia Corte, se encuentran 15 tipos diferentes de medidas, una parte significativa en acciones de control concentrado de constitucionalidad. 
Cabe resaltar que hubo convergencia entre el Poder Legislativo y el Poder Judicial en cuanto a la necesidad de tratamiento urgente de la pandemia. Fueron atendidas las medidas de urgencia requeridas por el Poder Ejecutivo y concedida seguridad jurídica a este para hacer los gastos extraordinarios, sin preocuparse con los límites presupuestales o con la infracción de normas de responsabilidad fiscal ordinariamente aplicables.

No se puede decir, en Brasil, por tanto, que el Poder Ejecutivo haya sufrido bloqueos institucionales para enfrentar la pandemia $y$, si hubo ineficiencia, esta se dio por los problemas en la planeación y/o ejecución de las medidas de responsabilidad del propio Poder Ejecutivo, algunas de ellas, objeto de control legislativo o judicial, lo que se pasa a analizar.

\subsection{Medidas de enfrentamiento económico y sanitario}

El Congreso Nacional declaró Estado de Calamidad Pública, el 20.03.2020, por medio del Decreto Legislativo No. 6 de 2020, conforme solicitación presidencial, limitando los efectos de la declaración al art. 65 de la Ley Complementar No 101/2000, por tanto, apenas a los efectos fiscales y de suspensión de la limitación de gastos públicos previstos en la referida ley, con validez hasta el 31.12.2020, lo que puede ser prorrogado.

En todos los demás aspectos, el funcionamiento de los tres poderes siguió normal, sin la concesión de ningún poder extraordinario al presidente de la república, que ya tiene competencia constitucional para expedir Medidas Provisorias (en adelante, MP), con efecto de ley, en caso de urgencia y relevancia, estas, con validez limitada y sujetas a ratificación o no por el Congreso.

La autorización para ampliar los gastos públicos para contención de la pandemia también fue objeto de decisión preliminar, proferida en Medida Cautelar (en adelante MC) incidental a la Acción Directa de Inconstitucionalidad (en adelante, ADI) No. 6.357 MC/DF, que desobligó al presidente de la república de cumplir el techo de gastos públicos en ese campo particular.

La principal medida para contener la crisis económica fue el pago de un auxilio de emergencia en el valor de $\mathrm{R} \$ 600,00$ (seiscientos reales) mensuales (poco más de cien dólares) por persona, hasta el límite de dos personas por familia, por tres meses, prorrogados por dos más, lo que atendió a más de sesenta millones de personas sin empleo formal, con prórroga hasta diciembre de 2020, con valor probable de la mitad del pago anterior, conforme a propuesta de la Presidencia de la República.

Hay problemas para el cobro del beneficio por personas muy pobres, como los habitantes de calle, debido a los requisitos exigidos para inscripción (documento individual fiscal regular y acceso a internet). La medida abrió el debate sobre la necesidad de inclusión digital, implementación de una renta básica permanente y tributación de grandes fortunas, temas que encuentran resistencia en el actual gobierno.

La autorización del gasto extraordinario para el pago de ese auxilio se dio por medio de la MP 937/2020, complementada por otras sucesivas. El beneficio fue aprobado por la Ley 13.982/2020, que aumentó el valor del auxilio, con relación al inicialmente negociado por el gobierno, que era de una tercera parte del valor aprobado (menos de 40 dólares). Fue uno de los primeros resultados del contrapeso del Congreso en una negociación en torno al enfrentamiento de la pandemia.

En lo que se refiere a las actividades económicas, diversas medidas provisionales dieron la concesión de créditos extraordinarios a diferentes ministerios para la adquisición de equipos o implantación de programas de crédito y estímulo a la economía, aspectos relacionados a la aviación civil y transporte terrestre, suspensión del ajuste anual de precio de los medicamentos, suspensión temporal de pagos de tributos, suspensión de las clases presenciales y adecuación del calendario escolar, flexibilización de los contratos 
laborales y concesión de créditos para apoyo a empresas, entre otras.

Al respecto, las principales leyes de la materia son la Ley Complementar 173/2020, relativa a la limitación de gastos públicos, inclusive con la contratación de funcionarios públicos durante la pandemia. También la Ley 14.019/2020, sobre higienización pública y uso obligatorio de protección facial en espacios públicos, con relación a la cual fue derribado el veto presidencial al uso obligatorio de mascarilla en "establecimientos comerciales e industriales, templos religiosos, establecimientos de enseñanza y demás locales cerrados en donde haya reunión de personas", siguiendo la recomendación de las autoridades sanitarias.

Otra norma relevante fue la Ley No. 14.010 de 2020, que dispone sobre el régimen jurídico de emergencia y transitorio de las relaciones jurídicas de derecho privado durante la pandemia, con relación a la cual fue derribado el veto presidencial al artículo que prohibía la concesión de decisión liminar para despejo durante la pandemia, salvo situaciones excepcionales, restableciendo la prohibición.

Además, el STF, en el ámbito de la Impugnación de Incumplimiento de Precepto Fundamental (en adelante, ADPF, conforme sigla en portugués) ADPF No. 672 y de una Reclamación (en adelante, RCL), la RCL 39976, reconoció la competencia concurrente de los entes federativos para adopción de medidas de enfrentamiento a la pandemia, lo que pudo hacer que medidas como el uso de mascarillas y las medidas de aislamiento social fueran determinadas por alcaldes y gobernadores, mucho antes de la Ley Nacional, ante a la resistencia del presidente con relación a tal materia. Por otro lado, el STF también intervino en la regulación del pacto federativo para deferir la entrega de ventiladores comprados por gobernadores, ante a actos expropiatorios de la Unión (Acción Civil Originaria, en adelante, ACO, de números 3398/R0 y 3385/MA).

En la Medida Cautelar incidental a la ADI 6341-DF, fue concedida autorización preliminar al presidente de la república para decidir sobre servicios esenciales, observadas las competencias de cada esfera, en la forma de la Constitución, de modo que, salvo si hay decisión contraria inferior en el límite de cada competencia, las actividades esenciales pueden funcionar a partir de decretos presidenciales que suelen dar interpretación elástica al concepto de servicio esencial.

Por otro lado, la Medida Cautelar concedida en la ADI 6421-DF (y, en el mismo sentido, en las ADIs 6422/DF, 6424/DF, 6425/DF, 6427/DF, 6428/DF y 6431/DF), dio interpretación conforme a la Constitución en cuanto al art. $2^{\circ}$ de la MP 966/2020 estableciendo que el "error grosero" no exime de la responsabilidad que tiene el dirigente con relación a los actos practicados para la contención de la pandemia, determinando la observancia de los criterios técnicos e científicos, especialmente, las recomendaciones de las organizaciones nacional e internacionalmente reconocidas y los principios constitucionales de precaución y prevención; lo que está acorde a la Resolución No. 1/2020 de la Comisión Interamericana de Derechos Humanos.

Hubo iniciativa legislativa para concesión de beneficio a algunos grupos específicos, como el apoyo al sector cultural, por medio de la Ley 14.017/2020, denominada Ley Aldir Blanc, en homenaje a importante músico brasileño víctima de la COVID-19, y el Proyecto de Ley 735/2020, que beneficia trabajadores del campo con una ayuda económica similar al auxilio de emergencia, con duración total de cinco meses, pero vetado por el presidente de la república en cuanto a la mayoría de los artículos, inclusive, con relación al pago del auxilio de emergencia, lo que será reexaminado por el Congreso.

En este momento, el país está sumergido en el dilema de como avanzar en algunos programas de incentivo económico $\mathrm{y}$, al mismo tiempo, no abandonar la agenda neoliberal que disminuye la intervención del Estado en la economía y recorta gastos públicos, dos medidas ineficaces para 
contener las consecuencias de una crisis de gran proporción.

Además de las privatizaciones, siguen siendo cogitadas reformas tributarias regresivas y más destitución de derechos laborales, desconsiderándose que el aumento de la pobreza y del desempleo aumentará la demanda por asistencia social y económica del Estado, lo que es incompatible con la pretensión de reducir los gastos públicos con servicios sociales.

La ideología neoliberal y la intencional exclusión de sectores o temas sociales de la agenda gubernamental traban la aplicación hasta mismo de los valores autorizados por el Congreso, de modo que la no ejecución del presupuesto aprobado en materia de protección a los DESCA y a los grupos vulnerables es otra estrategia utilizada para recortar gastos de políticas sociales en Brasil $^{33}$.

\subsection{Medidas de combate al racismo estructural 0 de protección a las minorías vulnerables y al medio ambiente}

Tres grupos vulnerables fueron objeto de acciones de control específicas, durante la pandemia, a razón de omisión y/o discriminación del Poder Ejecutivo: los encarcelados, los indígenas y las comunidades predominantemente formadas por afrodescendientes, todos ellos víctimas de racismo estructural, con efectos perversos durante la pandemia, pues los tornó aún más vulnerables a las muertes por COVID-19.

La Ley 14.021/2020 instituyó medidas específicas de combate a la pandemia entre los indígenas y otros grupos vulnerables, como los migrantes, las comunidades de remanentes de esclavos (quilombolas), pescadores artesanales y otros grupos 0 comunidades tradicionales, pero sufrió

33. Los medios de comunicación destacaron, durante la pandemia, la ausencia de ejecución del presupuesto para contención de los cambios climáticos, de protección indígena, para combate a la pandemia (adquisición de medicamentos, ventiladores, equipos médicos) del Ministerio de salud, entre otros. varios vetos presidenciales, algunos derribados, como, por ejemplo, la obligación de fornecimiento de agua potable, limpieza y desinfección de resguardos indígenas, el fornecimiento de lechos hospitalarios, UCIs y ventiladores para atendimiento a esa población en el subsistema de salud a ella aplicable (SasiSUS) ${ }^{34}$.

Además, en la ADPF 709-DF, el STF reconoció que la actuación del Estado para proteger a los indígenas durante la pandemia es insuficiente, de modo que determinó la aplicación de las siguientes medidas en sede cautelar:

“1. SALA DE SITUACIÓN: Que el gobierno federal instale Sala de Situación para gestión de acciones de combate contra la pandemia con relación a los pueblos indígenas aislados $o$ de contacto reciente, con participación de las comunidades, por medio de la APIB, de la Procuraduría General de la República y de la Defensoría Pública de la Unión. Los miembros deberán ser designados en 72 horas a partir de la ciencia de la decisión, y la primera reunión virtual debe ser convocada en 72 horas después de la indicación de los representantes;

2. BARRERAS SANITARIAS: Que en 10 días, a partir de la ciencia de la decisión, el gobierno federal escuche la Sala de Situación y presente un plan de creación de barreras sanitarias en tierras indígenas;

3. PLAN DE ENFRENTAMIENTO DE LA COVID-19: Que el gobierno federal elabore en 30 días, a partir de la ciencia de la decisión, con la participación de las comunidades y del Consejo Nacional de Derechos Humanos, un Plan de Enfrentamiento de la COVID-19 para los Pueblos Indígenas Brasileños. Los representantes de las comunidades

34. Conforme consta em la página web específica, la Secretaria Especial de Salud Indígena (SESAI) es la responsable por coordinar y ejecutar la Política Nacional de Atención a la Salud de los Pueblos Indígenas y todo el proceso de gestión del Subsistema de Atención a la Salud Indígena (SasiSUS) en el Sistema Único de Salud (SUS). 
deberán ser definidos en 72 horas a partir de la ciencia de la decisión;

4. CONTENCIÓN DE INVASORES: Que el gobierno federal incluya en el Plan de Enfrentamiento y Monitoreo de la COVID-19 para los Pueblos Indígenas medida de contención y aislamiento de invasores con relación a tierras indígenas. Destacó, todavía, que es deber del gobierno federal elaborar un plan de desintrusión y que se nada fuera hecho, volverá al tema.

5. SUBSISTEMA INDÍGENA: Que todos los indígenas en resguardos tengan acceso al Subsistema Indígena de Salud, independiente de la homologación de las tierras o resguardos; y que los que no viven en resguardos también accedan al subsistema en la falta de disponibilidad del SUS general ${ }^{35}$.

La decisión está bajo seguimiento por el STF, pero otras violaciones siguen ocurriendo en contra de esa población, como los intentos de reconocimiento de títulos propietarios de tierras en tierras indígenas no homologadas; el retraso deliberado en las demarcaciones y homologaciones de los títulos de tierras y la persistente ocupación de esas tierras por minería ilegal y madereros, con apoyo tácito del gobierno, al impedir que medidas de desocupación de las tierras sean cumplidas por los funcionarios encargados de la protección ambiental.

Por la similitud con lo que está ocurriendo en otros países de la región, se nota el intento neocolonial de expulsar a los indígenas de sus resguardos por disputa de tierras o de los recursos existentes en el suelo y subsuelo, lo que, en la práctica, configura política de exterminio de esa población.

En otra Medida Cautelar incidental propuesta para protección de grupos vulnerables, en el ámbito de la ADPF 635-RJ, el STF prohibió la realización de operaciones policiales en favelas de Rio de Janeiro

35. Traducción libre de la autora a partir del texto literal de la decisión. durante la pandemia. Eso se dio después de la muerte de un adolescente en su casa durante una operación policial realizada sin protocolos de seguridad. Las muertes por "bala perdida" o por "desaparición forzada", especialmente, en Rio de Janeiro y São Paulo, son una realidad que afecta, todos los años, a diversas personas, inclusive, a niños y niñas. Las operaciones violentas y descuidadas en barrios pobres es otro ejemplo de racismo estructural persistente en Brasil ${ }^{36}$.

Con relación a la protección de los encarcelados, medidas de urgencia fueron requeridas en las acciones ADPF 684-DF y ADPF 347-DF y, mientras no se decide la cuestión de fondo, hubo recomendación del STF, en la ADPF 347- DF, para que los jueces de ejecución penal concedan los siguientes beneficios a los encarcelados:

a) libertad condicional a encarcelados con edad igual o superior a sesenta años, en los términos del art. $1^{\mathrm{o}}$ de la Ley No. 10.741, de 1ํ de octubre de 2003;

b) régimen domiciliario a los seropositivos para VIH, diabéticos, portadores de tuberculosis, cáncer, enfermedades respiratorias, cardíacas, inmunosupresoras $\mathrm{u}$ otras susceptibles de agravamiento a partir del contagio por COVID-19;

c) régimen domiciliario a las gestantes y lactantes, en la forma de la Ley No. 13.257, de 8 de marzo de 2016 - Estatuto de la Primera Infancia;

d) régimen domiciliario a reclusos por crímenes cometidos sin violencia o grave amenaza; e) sustitución de la prisión provisoria por medida alternativa a

36. La omisión de los poderes públicos en actuar para proteger esas poblaciones generó muchos ejemplos de auto organización para combatir la COVID-19, como ocurrió en las favelas de Paraisópolis, em São Paulo, y Rocinha, en Rio de Janeiro. El Atlas de la violencia del año de 2020 revela que los negros son la principal víctima de la violencia en Brasil, más de $70 \%$ de las muertes por la policia, que siguen aumentando en comparación al asesinato de blancos en el mismo período < https:// www.ipea.gov.br/atlasviolencia/ > 
razón de delitos practicados sin violencia u grave amenaza;

f) medidas alternativas a presos em flagrante ante el cometimiento de crímenes sin violencia u grave amenaza;

g) progresión de pena a quien, atendiendo el criterio temporal, aguarda el examen criminológico;

y h) progresión anticipada de la pena a los presos sometidos al régimen semi abierto $^{37}$.

Muchos habeas corpus, inclusive, colectivos, fueron concedidos para alterar el régimen de cumplimiento de pena y uno de los más recientes trata del hacinamiento en institución socioeducativa (institución destinadas a internación de menores en conflicto con la ley), en la cual fueron determinadas medidas para su contención, inclusive, con la posibilidad de conversión de la internación institucional en domiciliaria (Habeas Corpus, en adelante, HC, No 143998- ES).

Esas medidas actúan apenas en los efectos nocivos superficiales del modelo económico vigente, pues, tanto la ausencia de foco en políticas de generación de trabajo, empleo y renta dignos, cuanto la ausencia de inversión en políticas públicas de inclusión y seguridad sociales, aumentan los problemas que el Poder Judicial es llamado a resolver.

\subsection{Medidas de protección a los derechos fundamentales y sus garantías}

La MP 927/2020 instituyó diversas medidas flexibilizadoras en el ámbito laboral, pero la Medida Cautelar concedida en la ADI 6.342-DF suspendió dos de sus artículos, el que impedía el reconocimiento de la COVID-19 como enfermedad ocupacional y el que impedía la actuación punitiva de la auditoría fiscal del trabajo durante la pandemia en caso de ilícitos laborales

37. ADPF 347- DF, MP Marco Aurelio. Traducción libre de la autora de trecho de la decisión. específicos, incluido el registro del empleado. Estas fueron dos importantes medidas para proteger la salud de los trabajadores y evitar abusos laborales, incluido el trabajo forzoso, frecuentemente encontrado en Brasil, inclusive, durante la pandemia.

En otras Medidas Cautelares concedidas en la ADI 6.351-DF y en la ADPF-DF, fue suspendida la eficacia del art. $6^{\circ}-\mathrm{B}$ de la Ley $13979 / 2020$, incluido por la MP 928/2020, que suspendía plazos de la Ley de acceso a la información durante la pandemia y para obligar al ministro de salud a que mantuviera la difusión de los datos epidemiológicos relativos a esta, inclusive en la página web del Ministerio de Salud, con información de los datos acumulados de las ocurrencias relativas a la enfermedad.

El derecho a la privacidad fue protegido en la ADI 6387/DF y otras (ADIs 6388DF, 6389-DF, 6390-DF y 6393-DF), para conceder Medida Cautelar suspendiendo la eficacia de la MP 954/2020, que autorizaba la transferencia de datos de empresas de comunicación o de servicios telefónicos para el Instituto Brasileño de Geografía y Estadística (IBGE) por considerarse que la violación no era justificada, por el riesgo de mal uso de las informaciones obtenidas así.

Otras medidas fueron tomadas en los últimos años por el STF para mantener otros derechos políticos básicos, como el derecho a la libre reunión, libertad de expresión y de manifestación del pensamiento, inclusive, en contra del propio STF (Petición, en adelante, PET, No 8830 MC/DF).

Para preservar el comando constitucional que asegura la democracia participativa y las atribuciones constitucionales del Poder Legislativo, en la ADI 6121 MC/DF se suspendió la eficacia de la extinción de Consejos previstos en Ley, con la siguiente determinación:

Concedo parcialmente la medida preventiva para, suspendiendo la eficacia del $\S 2$ 을 del artículo $1^{\circ}$ del Decreto № $9.759 / 2019$, en la redacción dada por el Decreto № 9.812/2019, apartar, hasta el 
examen definitivo de esta acción directa de inconstitucionalidad, la posibilidad de extinción, por acto unilateralmente editado por el Jefe del Poder Ejecutivo, de colegiado cuya existencia encuentre mención en ley en sentido formal, aún que ausente expresa referencia "sobre la competencia u la composición". Por conexión, suspendo la eficacia de actos normativos posteriores que promuevan, en la forma del artículo 9o del Decreto № 9.759/2019, la extinción de los órganos.

Recientemente, en Medida Cautelar requerida en la ADPF $722 \mathrm{MC} / \mathrm{DF}$ el STF también dictó sentencia que protege las libertades públicas al prohibir órgano de inteligencia del gobierno de elaborar informes en contra de funcionarios públicos, inclusive, profesores, por motivación de opinión política. En el caso, 579 funcionarios públicos, identificados como "antifascistas", fueron investigados por sus opiniones políticas, en conducta similar a las prácticas de "caza a las brujas" de la dictadura militar.

A pesar de los diversos problemas identificados en la conducta presidencial, hay resistencia del Congreso en procesar alguno de los 56 pedidos de impeachment en contra del actual presidente (Jiménez, 2020). Estudiosos del tema apuntan diversos actos que podrían ser tipificados como crimen de responsabilidad $^{38}$, lo que refuerza el anterior análisis acerca de los problemas de aplicación de tal instituto en Brasil.

\section{CONSIDERACIONES FINALES - A PROPÓSITO DE BUSCAR SALIDAS PARA LAS CRISIS}

En el caso brasileño, como se vio, la gestión de las crisis sanitaria y económica impuso más pérdida de DESCAs y restricciones a derechos civiles y políticos que propiamente restricción al derecho de ir y venir.

38. Hubner (2019) apunta, en agosto de 2019, 17 crímenes de responsabilidad ya cometidos por el presidente de la república hasta aquel entonces. Todos los hechos comentados en este artículo son posteriores a tal análisis, lo que revela que otros tantos actos que podrían ser tipificados como crímenes de responsabilidad fueron practicado desde entonces.
El elevado número de vidas perdidas y la prorrogación de los efectos económicos de la pandemia son consecuencia de la falta de coordinación nacional y de las medidas inadecuadas adoptadas por el Poder Ejecutivo, agravadas por el veto a algunas de las medidas propuestas por el Poder Legislativo y por el retraso en cumplir políticas aprobadas y decisiones judiciales.

La ineficacia de las políticas propuestas en el plan nacional refleja, por otro lado, compromiso con valores del ideario neoliberal que terminan por sobreponer la protección económica del mercado a la protección de las personas.

Eso impone al Poder Judicial una sobrecarga de trabajo inalcanzable para contener los efectos nocivos de decisiones políticas que caracterizan violaciones sistemáticas de derechos fundamentales. A la par de lo anterior, las limitaciones existentes en el diseño institucional de los tres poderes generan desequilibrios que impiden una adecuada protección de la democracia sustantiva y participativa en Brasil.

Además, considerando que la agenda de reformas económicas tuvo vía libre durante la pandemia, se observa que la calamidad pública terminó por transformarse en un verdadero estado de excepción, que facilita las conductas antidemocráticas, violatorias y destituyentes de derechos, sin suficientes debates, justo cuando la sociedad no puede participar plenamente de la agenda pública y, por tanto, no logra movilizarse o defenderse adecuadamente de los ataques a sus derechos.

Por fin, se entiende que la comprensión histórica de los problemas estructurales del país, acompañada de una escucha plural, pueden ayudar a romper la cultura autoritaria vigente y enfrentar los problemas de modo estructural.

Las prácticas dialógicas necesitan ser incorporadas en el ámbito de los tres poderes, observando los métodos deliberativos aplicables en el campo de los derechos humanos, que exigen inclusión, no 
discriminación, trasparencia, rendición de cuentas y participación ciudadana.

La decisión tomada en la ADPF 709. DF es un experimento relevante durante la pandemia. Tal tipo de decisión exige seguimiento competente y reconocimiento de las formas sutiles usadas actualmente para erosionar la democracia. Se debe reconocer que son los funcionarios públicos los que, de hecho, ejecutan las políticas que retiran las leyes del papel y que para proteger algunos derechos es necesario proteger ciertas garantías, incluidas, algunas instituciones públicas en contra de la injerencia indebida y del vaciamiento de su estructura y competencias, lo que se aplica a las instituciones de protección a los pueblos indígenas de Brasil, entre otras.

Hay un espacio abierto para las instituciones democráticas auto reformarse y eso es urgente para contrarrestar los efectos de un hiperpresidencialismo abusivo. Para tanto, es necesario percibir la importancia de implementar cambios en la cultura institucional a fin de superar los vacíos de aplicación de las normas de protección a los derechos humanos (nacionales e internacionales) y de sus garantías, así como para que se empiecen a adoptar, de modo institucionalizado, prácticas que mejoren la confianza institucional y aseguren la inclusión, no discriminación, participación plural, trasparecía y la rendición de cuentas.

\section{REFERENCIAS BIBLIOGRÁFICAS}

\section{Libros, capítulos de libros y artículos de periódicos especializados}

» Agamben, G. (2004). Homo Sacer. O poder soberando e a vida nua I. Belo Horizonte, UFMG.

» Codato, A. N. (2005). Uma história política da transição brasileira: da ditadura militar à democracia. Revista Sociologia Política, (25), 83-106. Recuperado de http://www.scielo.br/pdf/rsocp/n25/31113.pdf

» Comparato, F. K. (2017). A oligarquia brasileira: visão histórica. São Paulo: Editora Contracorrente. Kindle book.

» D'Araújo, M. C. (2012). O estável poder de veto Forças Armadas sobre o tema da anistia política no Brasil. Varia História, 28 (48), 573-597. Recuperado de http:// www.scielo.br/pdf/vh/v28n48/06.pdf

» Freitas, G. M., \& Bustamante, T. R. (2017). Separação e equilíbrio de poderes: reflexões sobre democracia e desenho institucional do STF pós-1988. Apontamentos a partir de um estudo de caso: ADPF 402-DF. Cadernos Adenauer, XVIII (1), 193216. Recuperado de http://www.kas.de/wf/doc/23078-1442-5-30.pdf

» Koerner, A. \& Freitas, L. B. (2013). O Supremo na Constituinte e a Constituinte no Supremo. Lua Nova, (88), 141-184. Recuperado de http://www.scielo.br/pdf/ $\ln /$ n88/a06n88.pdf

» Landau, D. (2013). Abusive Constitucionalism. University of California, Davis, 47 (189): 189-260.

» Levitsky, Steven; Ziblatt, Daniel. (2018) Como as democracias morrem (Locais do Kindle 4-8). Zahar. Edição do Kindle.

» Mbembe, A. (2020). Brutalisme. Paris: La Découverte.

» Mbembe, A. (2006). Necropolitique. In: Raisons politiques, (21), 29-60. Presses de Sciences Po. Recuperado de https://www.cairn.info/revue-raisons-politiques- 
2006-1-page-29.htm

» Gargarella, R. (2014). La sala de máquinas de la Constitución. Buenos Aires: Katz.

» Gaspari, E. (2017). Coleção ditadura. Río de Janeiro: Intrínseca. Kindle book.

» Ginsburg, T.; Hug, A.Z. (2018) How to Save a Constitutional Democracy. University of Chicago Press. Edição do Kindle.

» Orbegozo, B. V. (2015). Colombia no es una isla. Una contribución al debate sobre la formación del Estado colombiano en el entorno global. Bogotá: Universidad Externado de Colombia.

» Russel-Wood, A. J. (1998). Centros e periferias no mundo luso-brasileiro, 15001808. Revista Brasileira de História, 18. Recuperado de http://www.scielo.br/scielo.php?script=sci_arttext\&pid=S0102-01881998000200010\&lng=não\&nrm=não \&tlng=pt

» Sarmento, D. (2009). 21 anos de 1988: a Assembléia Constituinte de 1987/1988 e a experiência constitucional brasileira sob a Carta de 1988. DPU, 6 (30), 7 - 41.

» Silva Filho, J. C. M. (2011). O terrorismo de Estado e a ditadura civil-militar no Brasil: direito de resistência não é terrorismo. The Third Session of the International Forum on Crime and Criminal Law in the Global Era. Beijing. Anais do Congresso: 50 - 75. Recuperado de http://repositorio.pucrs.br/dspace/ bitstream/10923/11337/2/O_Terrorismo_de_Estado_e_a_Ditadura_Civil_Militar_ no_Brasil_Direito_de_Resistencia_nao_e_Terrorismo.pdf

» Souza, J. (2017). A elite do atraso: da escravidão à Lava Jato. Río de Janeiro: Leya.

» Streeck, W. (2017). El ascenso del Estado consolidador europeo. En: W. Streeck, ¿Cómo terminará el capitalismo? Ensayos sobre un sistema en decadencia (pp. 142173). Madrid: Traficantes de sueños.

\section{Tesis}

» Fernandes, P. (2005). A produção legal da ilegalidade: os direitos humanos e a cultura jurídica brasileira. USP. São Paulo. Recuperado de http://www.dominiopublico.gov.br/download/texto/ea000233.pdf.

» Freitas, G.M.B. (2020) Protección a los derechos económicos, sociales, culturales y ambientales (DESCA), cultura jurídica y constitucionalismo dialógico. Modelo deliberativo de aplicación e implementación de los DESCA a partir del estudio de caso del derecho al agua en Colombia y de los desafíos para su aplicación en Brasil. Universidad Externado de Colombia y Universidad Federal de Minas Gerais. Bogotá/Belo Horizonte.

\section{Notícias, informes y artículos de periódicos}

» Camarotto, M. (17 de julio de 2020). Número de militares no governo mais do que dobra com Bolsonaro. Recuperado de: <https://valor.globo.com/politica/ noticia/2020/07/17/numero-de-militares-no-governo-mais-do-que-dobra-combolsonaro.ghtml>

" Cárdenas, J. (22 de marzo de 2019). El país. Economía del extermínio. Recuperado de https://elpais.com/internacional/2019/01/22/colom- 
bia/1548120869_653877.html

» Colucci, C. (14 de abril de 2020). Covid-19 gera inflamação no coração e pode levar a infarto. Sociedade de Cardiologia monta registro nacional de complicações cardíacas para avaliar o impacto. Recuperado de <https://www1.folha.uol.com. br/equilibrioesaude/2020/04/covid-19-gera-inflamacao-no-coracao-e-pode-levar-a-infarto.shtml>

» Comisión Interamericana de Derechos Humanos (2020). Resolución 1 de 2020 [CIDH, Resolución 1, 2020]. Pandemia y Derechos Humanos en las Américas. Recuperado de <http://oas.org/es/cidh/decisiones/pdf/Resolucion-1-20-es.pdf>

» Florios, D. (14 de enero de 2016). A economia neoliberal mata mais que todos os exércitos do mundo. Recuperado de <https://www.greenme.com.br/informarse/green-economy/2736-a-economia-neoliberal-mata-mais-que-todos-os-exercitos-do-mundo/>

» G1. Jornal Nacional. (25 de junio de 2020). Estoque de medicamentos usados em UTIs está zerado em 21 estados e no DF, diz levantamento. Recuperado de $<$ https://g1.globo.com/jornal-nacional/noticia/2020/06/25/estoque-de-medicamentos-usados-em-utis-esta-zerado-em-21-estados-e-no-df-diz-levantamento. ghtml>

» Hubner, C. (22 de agosto de 2019). 17 crimes de responsabilidade. Bolsonaro tem fé na impunidade que catapultou sua trajetória. Época. Recuperado de $<$ https://epoca.globo.com/conrado-hubner-mendes/17-crimes-de-responsabilidade-23894352>.

» Instituto de Pesquisas Económicas Aplicadas (IPEA). (2020). Atlas da Violência. Recuperado de < https://www.ipea.gov.br/atlasviolencia/ >

» Jiménez, C. (11 de agosto de 2020). El país. Movimentos negros apresentam $56^{\circ}$ pedido de impeachment de Bolsonaro, por negligência com a pandemia. Recuperado de <https://brasil.elpais.com/brasil/2020-08-11/movimentos-negrosapresentam-56-pedido-de-impeachment-de-bolsonaro-por-negligencia-com-apandemia.html>

» Kruse, T. (20 de mayo de 2020). 0 Estado de São Paulo. Coronavírus supera câncer e enfarte; por dia já é a primeira causa de morte no país. Recuperado de https://saude.estadao.com.br/noticias/geral,coronavirus-supera-cancer-e-enfarte-por-dia-ja-e-a-1-causa-de-mortes-no-pais,70003309136

» Lisandra, A.; Fonseca, P. (08 de agosto de 2020). Com 100 mil mortes, Covid mata em menos de 6 meses mesmo número de brasileiros que HIV matou em 9 anos. Recuperado de https://www.msn.com/pt-br/news/brasil/com-100-milmortes-covid-mata-em-menos-de-6-meses-mesmo-n-c3-bamero-de-brasileirosque-hiv-matou-em-9-anos/ar-BB17HMgp.

» Mota, C.V.; Guimarães, L.; Alvim, M.; Barifouse, R.; Lemos, V. (08 de agosto de 2020). Coronavírus: 9 erros que levaram às 100 mil mortes no Brasil (e 1 lição que a pandemia deixa até agora). Recuperado de https://www.bbc.com/portuguese/ brasil-53703044.

» Naciones Unidas. Comité de Derechos Económicos, Sociales y Culturales (17 de abril de 2020). Declaración sobre la pandemia de enfermedad por coronavirus (COVID-19) y los derechos económicos, sociales y culturales. Recuperado de < https://undocs.org/es/E/C.12/GC/25 >

» Naciones Unidas. Comité de Derechos Económicos, Sociales y Culturales (30 de 
abril de 2020). Observación General No. 25, relativa a la ciencia y los derechos económicos, sociales y culturales. Recuperado de < https://undocs.org/es/E/C.12/ $\mathrm{GC} / 25>$

» Paraguassu, L.; Fonseca, P. (07 de agosto de 2020). Covid iguala em 6 meses mesmo no de mortes da HIV em 9 anos. Recuperado de https://www.terra.com.br/ noticias/brasil/covid-iguala-em-6-meses-mesmo-n-de-mortes-da-hiv-em-9-anos, f188da9a02f5d0398dcc143addab6eb4oo2x6tzm.html

» Presidencia de la República. Brasil. Secretaria General (2015a). Índice de vulnerabilidade juvenil à violência e desigualdade racial 2014. Brasília: Presidência da República. Recuperado de http://unesdoc.unesco.org/ images/0023/002329/232972POR.pdf.

» Presidencia de la República. Brasil. Secretaria General (2015b). Mapa do encarceramento: os jovens do Brasil. Brasília: Presidência da República. Recuperado de http://juventude.gov.br/articles/participatorio/0010/1092/Mapa_do_Encarceramento_-_Os_jovens_do_brasil.pdf.

» Setipa, J. (19 de mayo de 2020). Como resolver a escassez de equipamentos no combate à pandemia. Recuperado de <https://saude.abril.com.br/blog/com-apalavra/como-resolver-a-escassez-de-equipamentos-no-combate-a-pandemia/>

» Tajra, A. (11 de agosto de 2020). Covid: Defensorias públicas de 16 estados pedem liberdade a presas grávidas. Recuperado de <https://noticias.uol.com.br/ cotidiano/ultimas-noticias/2020/08/11/mulheres-gravidas-presas-sp-relatoscovid-19.htm>

» Varely, G. (07 de agosto de 2020). Brasil tem novo dia com mais de mil mortos pela covid-19. Fiocruz alerta: em três meses, serão 200 mil. Recuperado de <https://www.redebrasilatual.com.br/saude-e-ciencia/2020/08/brasil-tem-novo-dia-com-mais-de-mil-mortos-pela-covid-19-fiocruz-alerta-em-3-meses-serao200-mil/>.

» Vivas, F. (09 de octubre de 2018). De 513 deputados eleitos na Câmara, só 27 dependeram dos próprios votos para se eleger. Recuperado de <https://g1.globo. com/politica/eleicoes/2018/noticia/2018/10/09/de-513-deputados-eleitos-nacamara-so-27-dependeram-dos-proprios-votos-para-se-eleger.ghtml>

\section{Medidas Provisorias, Leyes y Decisiones judiciales}

» Câmara dos Deputados, Brasil. (18 de marzo de 2020). Ley no 735. [Proyecto de Ley 735 de 2020]. Recuperado de <https://www.camara.leg.br/proposicoesWeb/ prop_mostrarintegra;jsessionid=E1F7104384761F7FDD406BF424063B8E.prop osicoesWebExterno2? codteor $=1867396 \&$ filename $=\mathrm{PL}+735 / 2020>$

» Congreso Nacional, Brasil. (04 de mayo de 2000). Ley Complementar no 101. [Ley Complementar 101 de 2000]. Recuperado de <http://www.planalto.gov.br/ ccivil_03/Leis/LCP/Lcp101.htm>

» Congreso Nacional, Brasil. (27 de mayo de 2020). Ley Complementar no 173. [Ley Complementar 173 de 2020]. Recuperado de <http://www.planalto.gov.br/ ccivil_03/leis/lcp/Lcp173.htm>

» Congreso Nacional, Brasil. (06 de febrero de 2020). Ley no 13.979. [Ley 13.979 de 2020]. Recuperado de <http://www.planalto.gov.br/ccivil_03/_ato20192022/2020/Lei/L13979.htm> 
» Congreso Nacional, Brasil. (02 de abril de 2020). Ley no 13.982 . [Ley 13.982 de 2020]. Recuperado de < http://www.planalto.gov.br/ccivil_03/_ato20192022/2020/Lei/L13982.htm>

» Congreso Nacional, Brasil. (10 de julio de 2020). Ley no 14.010 . [Ley 14.010 de 2020]. Recuperado de <http://www.planalto.gov.br/ccivil_03/_Ato20192022/2020/Lei/L14010.htm>

»Congreso Nacional, Brasil. (29 de junio de 2020). Ley no 14.017 . [Ley 14.017 de 2020]. Recuperado de <http://www.planalto.gov.br/ccivil_03/_Ato20192022/2020/Lei/L14017.htm>

» Congreso Nacional, Brasil. (02 de julio de 2020). Ley no 14.019. [Ley 14.019 de 2020]. Recuperado de <http://www.planalto.gov.br/ccivil_03/_Ato20192022/2020/Lei/L14019.htm>

» Congreso Nacional, Brasil. (07 de julio de 2020). Ley no 14.021. [Ley 14.021 de 2020]. Recuperado de <http://www.planalto.gov.br/ccivil_03/_ato20192022/2020/lei/l14021.htm>

» Presidência da República. Brasil. (20 de marzo de 2020). Decreto n.o 6. [Decreto 6 de 2020]. DOU: 20.03.2020. Recuperado de <http://www.planalto.gov.br/ ccivil_03/portaria/DLG6-2020.htm>

» Presidência da República. Brasil. (22 de marzo de 2020). Medida Provisória no 927. [Medida Provisória 927 de 2020]. DOU: 22.03.2020. Recuperado de <http:// www.planalto.gov.br/ccivil_03/_Ato2019-2022/2020/Mpv/mpv927.htm>

» Presidência da República. Brasil. (23 de marzo de 2020). Medida Provisória no 928. [Medida Provisória 928 de 2020]. DOU: 23.03.2020. Recuperado de <http:// www.planalto.gov.br/ccivil_03/_ato2019-2022/2020/Mpv/mpv928.htm>

» Presidência da República. Brasil. (17 de abril de 2020). Medida Provisória no 954. [Medida Provisória 954 de 2020]. DOU: 17.04.2020. Recuperado de <http:// www.planalto.gov.br/CCIVIL_03/_Ato2019-2022/2020/Mpv/mpv954.htm>

» Presidência da República. Brasil. (13 de mayo de 2020). Medida Provisória no 966. [Medida Provisória 966 de 2020]. DOU: 14.05.2020. Recuperado de <http:// www.planalto.gov.br/ccivil_03/_Ato2019-2022/2020/Mpv/mpv966.htm>

» Supremo Tribunal Federal. (19 de junio de 2020). Medida Cautelar (MC) en ACO 3398MC/RO. [M.P. Luís Roberto Barroso] Recuperado de http://portal.stf.jus. $\mathrm{br} /$ processos/downloadPeca.asp?id=15343547646\&ext=.pdf

»Supremo Tribunal Federal. (20 de abril de 2020). Tutela Provisoria (TP) en ACO 3385TP/MA. [M.P. Celso de Mello] Recuperado de https://portal.stf.jus.br/processos/downloadPeca.asp?id=15342938537\&ext=.pdf

» Supremo Tribunal Federal. Sala Plena. (13 de junio de 2019). Medida Cautelar (MC) en ADI 6121MC/DF. [M.P. Marco Aurélio] Recuperado de http://portal.stf.jus. $\mathrm{br} /$ processos/downloadPeca.asp?id=15341826697\&ext=.pdf

» Supremo Tribunal Federal. (24 de marzo de 2020). Medida Cautelar (MC) en ADI 6341MC/DF. [M.P. Marco Aurélio] Recuperado de http://www.stf.jus.br/arquivo/cms/noticiaNoticiaStf/anexo/ADI6341.pdf

» Supremo Tribunal Federal. Sala Plena. (29 de abril de 2020). Medida Cautelar (MC) en ADI 6342MC/DF, refrendada en parte por la Sala Plena. [M.P. Alexandre de Moraes] Recuperado de http://portal.stf.jus.br/processos/detalhe. asp?incidente $=5880968$ 
» Supremo Tribunal Federal. Sala Plena. (30 de abril de 2020). Medida Cautelar (MC) en ADI 6351MC/DF, refrendada por la Sala Plena. Voto conjunto de las ADIs 6347, 6351 e 6353. [M.P. Alexandre de Moraes] Recuperado de http://portal.stf. jus.br/processos/downloadPeca.asp?id=15344001246\&ext=.pdf

» Supremo Tribunal Federal. (29 de marzo de 2020). Medida Cautelar (MC) en ADI 6357MC/DF. [M.P. Alexandre de Moraes] Recuperado de http://www.stf.jus. $\mathrm{br} /$ arquivo/cms/noticiaNoticiaStf/anexo/ADI6357MC.pdf

» Supremo Tribunal Federal. Sala Plena. (21 de maio de 2020). Medida Cautelar (MC) en ADI 6321MC/DF. Voto conjunto ADI 6344/DF, 6346/DF, 6348/DF, 6349/ DF, 6352/DF y 6354/DF [M.P. Luís Roberto Barroso] Recuperado de http://portal. stf.jus.br/processos/detalhe.asp?incidente $=5912207$

» Supremo Tribunal Federal. Sala Plena. (07 de mayo de 2020). Medida Cautelar (MC) en ADI 6387MC/DF, refrendada por la Sala Plena. [M.P. Rosa Weber] Recuperado de http://www.stf.jus.br/arquivo/cms/resumocovid/anexo/paginador.pdf

» Supremo Tribunal Federal. (17 de marzo de 2020). Medida Cautelar (MC) en ADPF 347/DF. [M.P. Luís Roberto Barroso] Recuperado de http://www.stf.jus.br/ arquivo/cms/noticiaNoticiaStf/anexo/ADPF347decisao.Covid19.pdf

" Supremo Tribunal Federal. (08 de abril de 2020). Decisión Liminar en ADPF 672/DF. [M.P. Alexandre de Morais] Recuperado de http://www.stf.jus.br/arquivo/cms/noticiaNoticiaStf/anexo/ADPF672liminar.pdf

» Supremo Tribunal Federal. (08 de julio de 2020). Medida Cautelar (MC) en ADPF 709/DF. [M.P. Luís Roberto Barroso] Recuperado de http://www.stf.jus.br/ arquivo/cms/noticiaNoticiaStf/anexo/adpf 709.pdf

» Supremo Tribunal Federal. Sala Plena. (20 de agosto de 2020). Medida Cautelar (MC) en ADPF 722/DF. [M.P. Carmem Lúcia] Recuperado de http://portal.stf.jus. $\mathrm{br} /$ processos $/$ detalhe.asp?incidente $=5967354$

» Supremo Tribunal Federal. Sala Plena (05 de agosto de 2020). Decisión Liminar en ADPF 635/RJ. [M.P. Edson Fachin] Recuperado de http://portal.stf.jus.br/processos $/$ detalhe .asp?incidente $=5816502$

» Supremo Tribunal Federal. Segunda Sala. (25 de agosto de 2020). Habeas Corpus (HC) 143998/ES. [M.P. Edson Fachin] Recuperado de http://portal.stf.jus.br/ processos/detalhe.asp?incidente $=5189678$

» Supremo Tribunal Federal. (07 de maio de 2020). Medida Cautelar (MC) en Petición PET 8830/DF. [M.P. Celso de Mello] Recuperado de http://www.stf.jus.br/ arquivo/cms/noticiaNoticiaStf/anexo/Pet8830decisao.pdf

» Supremo Tribunal Federal. (30 de abril de 2020). Reclamação (RCL) 39976/SP. [M.P. Luiz Fux] Recuperado de http://portal.stf.jus.br/processos/downloadPeca. asp?id=15342994525\&ext=.pdf 